\title{
QUALIDADE DE VIDA NO TRABALHO DE PROFISSIONAIS EXPATRIADOS PARA ÍNDIA E CHINA
}

\author{
Graziele Zwielewski* \\ grazizw@gmail.com
}

\section{Suzana da Rosa Tolfo*}

s.r.tolfo@ufsc.br

*Universidade Federal de Santa Catarina - Florianópolis, SC / Brasil

http://dx.doi.org/10.1590/1413-2311.0462015.53604

Recebido em 19/02/2015

Aprovado em 23/06/2016

Disponibilizado em 31/08/2016

Avaliado pelo sistema "double blind review"

Revista Eletrônica de Administração

Editora-chefe: Aurora Zen

ISSN 1413-2311 (versão "on line")

Editada pela Escola de Administração da Universidade Federal do Rio Grande do Sul.

Periodicidade: Quadrimestral

Sistema requerido: Adobe Acrobat Reader

\section{RESUMO}

Uma das formas encontradas pelas empresas com atuação internacional para desenvolver profissionais é por meio da expatriação. Porém, expatriar remete a mudanças significativas e consequentes alterações no modo como as pessoas percebem, interpretam e se comportam no meio em que passam a viver e trabalhar. Devido às mudanças psicossocioculturais e familiares enfrentadas, os expatriados e suas famílias ficam sem contingências para se sentirem seguros. Esses elementos citados impactam na qualidade de vida dessas pessoas, que precisam se adaptar a um novo contexto cultural, econômico, político, psicossocial, e muitas vezes são obrigadas a adiar projetos pessoais, deixar de conviver com a família, modificar suas relações sociais. A necessidade de adaptação na vida pessoal do expatriado gera reflexos na sua vida profissional, afetando suas relações com o trabalho. Este contexto complexo resultou no objetivo principal desta pesquisa, que foi o de caracterizar a percepção de profissionais brasileiros expatriados para a Índia e a China sobre a sua qualidade de vida no trabalho (QVT). A pesquisa foi qualitativa, descritiva com características exploratórias. Procedeu-se a um estudo de caso e os dados foram coletados por meio de entrevistas com dez profissionais brasileiros expatriados para a China e Índia e com a gestora do Departamento de Expatriados, além de análise de documentos da empresa. A análise dos dados foi documental e de conteúdo, feita através da triangulação de dados. Os resultados demonstram que uma expatriação com QVT é a que atende às expectativas pessoais e profissionais do expatriado, além de se preocupar com sua repatriação. A QVT para os expatriados requer mais do que os oito elementos considerados por Walton (1979) como importantes para sua avaliação, requer também considerar a diferença cultural existente entre os países de origem e de destino, além da inclusão do significado do trabalho para o profissional e a sua adaptação cultural. 


\title{
QUALIDADE DE VIDA NO TRABALHO DE PROFISSIONAIS EXPATRIADOS PARA ÍNDIA E CHINA
}

Palavras-chave: Expatriação; Qualidade de vida no trabalho; Adaptação cultural.

\section{QUALITY OF WORKING LIFE OF EXPATRIATED PROFESSIONALS FOR INDIA AND CHINA}

\begin{abstract}
One of the forms encountered by enterprises to develop professional is by expatriation, but expatriate refers to significant and consequent changes in the way people perceive, interpret and behave in the environment in which they live. Due to psychosocial, cultural and family faced changes, expatriates and their families are left without contingencies to feel safe. These elements cited impact on quality of life of these people, because they need to adapt to a new economic, political, psychosocial and cultural context are often forced to postpone personal projects, have to live far away from their family, changing their social relationships. The need for adaptation in the professional's personal lives generates reflections in professional life, affecting their relationships at work. This is a complex environment that resulted in the main objective of this research, which was to characterize the perception of expatriates to India and China about their quality of work life. The research was qualitative, descriptive with exploratory features. We chose the case study and data collection through interviews with ten Brazilian professional expatriated to China and India, interview with the manager of the Expatriates Department and analysis of company documents. Data analysis was documentary and content, made by triangulation of data. In the results it was realized that an expatriation with QWL is the one that serves expatriates' professional and personal expectations beyond worrying about their repatriation. The QWL for expatriates requires more than eight elements considered by Walton (1979) as important to their assessment, requires also consider the existing cultural differences between countries of origin and destination as well as the inclusion of the meaning of work for professional and cultural adjustment.
\end{abstract}

Keywords: Expatriation; Quality of working life; Cultural adaptation.

\section{CALIDAD DE VIDA DE TRABAJO DE PROFESIONALES EXPATRIADOS A LA INDIA Y CHINA}

\section{RESUMEN}

Una de las formas encontradas por las empresas a desarrollar profesional es por medio de la expatriación, pero expatriados se refiere a los cambios significativos y los cambios consecuentes en la forma en que las personas perciben, interpretan y comportarse en el entorno en que viven. Debido a cambios psicosocioculturais y familiares que enfrentan, expatriados y sus familias se quedan sin contingencias para sentirse seguro. Estos elementos citados impacto en la calidad de vida de estas personas, que tienen que adaptarse a un nuevo contexto económico, político, psicosocial y cultural a menudo se ven obligados a posponer proyectos personales, tienen que dejar de vivir con la familia, el cambio de las relaciones sociales. La necesidad de adaptación en la vida personal del profesional genera reflejos en la vida profesional, que afecte a sus relaciones con el trabajo. Este es un entorno complejo que dio lugar a que es el objetivo principal de esta investigación, que iba a caracterizar la

REAd | Porto Alegre - Edição 84 - Nº 2 - Maio / Agosto 2016 - p. 510 - 542 


\section{Graziele Zwielewski \& Suzana da Rosa Tolfo}

percepción de los expatriados a la India y China acerca de su calidad de vida laboral. La investigación fue de tipo cualitativo, descriptivo con las características exploratorio. Elegimos el caso de estudio y recopilación de datos a través de entrevistas con diez profesionales brasileños expatriados a China y la India, entrevista con el director del Departamento de expatriados y el análisis de documentos de la empresa. El análisis de datos fue documental y del contenido, hecho por la triangulación de datos. Los resultados se dieron cuenta de que la expatriación con CVL es que sirve a las expectativas personales de profesionales expatriados y más allá de la preocupación de la repatriación de la misma. El CVL para expatriados requiere más de ocho elementos considerados por Walton (1979) como importantes para su evaluación, requiere también considerar las diferencias culturales existentes entre los países de origen y destino, así como la inclusión del significado del trabajo para profesionales y su ajuste cultural.

Palabras Clave: Expatriación; La calidad de la vida laboral; Adaptación cultural.

\section{INTRODUÇÃO}

A presença global tornou-se objetivo estratégico das grandes empresas, que focam em diferentes mercados, e a internacionalização gradual dessas organizações exige novas políticas e demandas administrativas na gestão internacional de negócios. A pressão sobre os gestores, para atender a essas demandas em diferentes países, é constante, tal como a abertura de novos escritórios, o desenvolvimento de projetos, a instalação de novas tecnologias, o desenvolvimento de equipes interculturais, o desenvolvimento de carreira internacional, entre outras atividades capazes de conquistar ou manter vantagens no mercado externo.

Por sua vez, os profissionais envolvidos nessa abertura comercial em nível internacional são levados a interagir com outras culturas e gerir pessoas com valores culturais diferentes. As atribuições e a adaptação muitas vezes são difíceis, uma vez que as regras, leis e suas interpretações são distintas entre um país e outro. Isso faz as pessoas se sentirem sem conhecimentos e habilidades suficientes para lidar com algumas situações, pois, conforme a cultura de cada um, os processos cognitivos sobre comunicação e resolução de conflitos interpessoais serão diferentes (BREW et al., 2011).

Nessas condições, cresce a necessidade de habilidades interculturais aos empregados dessas empresas, que precisam se preparar para lidar com as diferenças entre legislações, situações políticas, econômicas e culturais. Isso impacta na Gestão de Pessoas, que passa a lidar com questões relacionadas ao envio de funcionários da empresa matriz para suas operações internacionais (SANTOS, 2003). Conforme levantamentos do Ministério do Trabalho e Emprego brasileiro (BRASIL, 2013), em 2011 foram recebidos 56 mil estrangeiros para trabalhar no Brasil, quase quatro mil a mais do que no ano 


\section{QUALIDADE DE VIDA NO TRABALHO DE PROFISSIONAIS EXPATRIADOS PARA ÍNDIA E CHINA}

anterior. Só no primeiro semestre de 2013, foram emitidos 26.545 vistos de trabalho para expatriados no Brasil, um aumento de 19\% com relação ao mesmo período de 2012.

Com a globalização da economia, as empresas se tornam mais competitivas e passam a focar no cliente em vez de no produto. Por isso, elas necessitam desenvolver estratégias para se diferenciar e conseguir atender a seus clientes internos e externos. Dentre os clientes internos estão os expatriados: profissionais enviados para outro país, por um período que se presume limitado (LACOMBE, 2004), acompanhados ou não de suas famílias, para desenvolver um trabalho no país anfitrião. Mas a sobrevivência nesses países, com culturas, hábitos, símbolos, valores e sistemas políticos diferentes dos seus, é difícil tanto para as empresas, que entram em mercados altamente turbulentos, quanto para os profissionais, que enfrentam o novo e o desconhecido sem um "manual de instruções".

Como afirmam Homem e Tolfo (2004), alguns profissionais ainda são "míopes para reconhecer outros mundos" e outras maneiras de viver e trabalhar além dos seus. Dessa forma, um dos maiores desafios da gestão intercultural é o de superar a dicotomia entre "nós" e "eles", adotando uma atitude de abertura para a compreensão dos sentidos enunciados pelos estrangeiros, "estranhos" (GONDIM; FISCHER, 2009). Alguns gestores de empresas comentam a dificuldade de compreender as diferentes legislações que regem as relações de trabalho em cada país. Os profissionais se deparam com nova equipe de trabalho; algumas famílias se sentem alvo de preconceitos; outras adiam seus projetos; filhos adolescentes vivem na ponte aérea, para conciliar a vida amorosa e a vida em família. Diante desses inconvenientes, as empresas precisam oferecer melhores condições físicas e psicológicas de trabalho.

Expatriar remete a mudanças significativas e consequentes alterações no modo como as pessoas percebem, interpretam e se comportam no meio em que vivem. Todos os elementos citados impactam na qualidade de vida dos expatriados, que precisarão se adaptar a um novo contexto cultural, econômico, político, psicossocial. Inclusive, muitas vezes o cônjuge que acompanha o profissional expatriado precisa abandonar sua carreira profissional no país de origem. Casos de retornos prematuros ou de comportamentos inadequados, como o do zagueiro brasileiro Breno, expatriado para Munique e principal suspeito de ter ateado fogo em sua própria residência (CASO DO ZAGUEIRO..., 2011), refletem os desafios enfrentados pelos expatriados, inseridos em um mundo desconhecido de representações e significados; e por gestores de empresas, despreparados para cuidar da qualidade de vida desses profissionais (BUENO; CORSO, 2004). Para o técnico intercultural Thomas Groll, o

isolamento social, decorrente da sua expatriação para a Alemanha, pode ter levado o zagueiro a cometer o ato extremo (CASO DO ZAGUEIRO..., 2011). Entrar em um país sem saber como se 


\section{Graziele Zwielewski \& Suzana da Rosa Tolfo}

comunicar, devido à diferença de idioma, e por não saber quais gestos são permitidos, sem conhecer as pessoas, sem possuir relações sociais, enfrentando possíveis diferenças nos valores e na religião local, tudo isso deixa o profissional e sua família sem contingências para se sentir seguros.

Como a qualidade de vida pessoal influencia e é influenciada pela qualidade de vida no trabalho, a rotina de trabalho de um expatriado implica em preocupações contínuas, que frequentemente se tornam crônicas, com decorrentes doenças e frustrações em sua vida pessoal e influenciando seu rendimento como profissional. Sendo assim, a preservação da saúde física e emocional dos expatriados e de suas famílias deve ser prioridade no gerenciamento internacional de pessoas, através da criação de ferramentas e iniciativas mais evidentes e diretas nos cuidados com a qualidade de vida no trabalho.

Além dos desafios mencionados, o expatriado estará sujeito a adaptar-se a nova hierarquia e nova alimentação; aumentar a capacidade de assumir riscos, inclusive riscos imperceptíveis, como a perda da sua autoconfiança e satisfação como profissional, caso não consiga ter habilidades interculturais suficientes para lidar com a nova equipe. Araújo, Bilsky e Moreira (2012) e Homem e Dellagnelo (2006) afirmam que os expatriados geralmente são transferidos para outros países com responsabilidades aumentadas e que, apesar do aumento da pressão e da instabilidade no seu cotidiano, seu nível de estresse precisa permanecer em equilíbrio, para que possa ser prevenido o seu adoecimento pelo trabalho.

Nesse sentido, buscou-se, na literatura, referências relacionadas à percepção desses profissionais sobre a expatriação e a qualidade de vida do trabalho. No entanto, não foram encontradas tais referências no banco nacional de dados do Portal Capes. Em função disso, considerou-se relevante produzir conhecimento científico sobre como as pessoas percebem a sua qualidade de vida no trabalho durante o processo de expatriação. A expatriação ainda é um fenômeno pouco explorado cientificamente, logo, uma pesquisa nessa área preenche algumas das lacunas sobre o assunto, assim como permite contribuir com organizações preocupadas com a criação de estratégias de gestão de QVT focadas no que o próprio sujeito considera importante para a sua qualidade de vida na expatriação. Portanto, o objetivo principal deste trabalho foi responder à seguinte pergunta:

Quais são as percepções de profissionais expatriados sobre sua qualidade de vida no trabalho na Índia e na China?

A pesquisa buscou responder à questão acima, no contexto de uma empresa situada no sul do Brasil, que tem atualmente profissionais expatriados em diversos países. Para trabalhar esses conceitos, 
QUALIDADE DE VIDA NO TRABALHO DE PROFISSIONAIS EXPATRIADOS PARA ÍNDIA E CHINA

estas autoras usaram o modelo de Walton (1979), por se tratar de uma perspectiva com contribuições à gestão e pela similaridade entre os itens formulados pelo autor e os questionamentos suscitados a partir da pergunta de pesquisa.

\section{QUALIDADE DE VIDA NO TRABALHO E EXPATRIAÇÃO}

Minayo (2000) afirma que qualidade de vida (QV) pressupõe a capacidade de efetuar uma síntese cultural de todos os elementos de determinada sociedade, ou seja, é a construção social com a marca da relatividade cultural, em que os elementos e valores culturais de cada época e contexto sociopolítico predominantes tornam as teorias sobre qualidade de vida dinâmicas. Pode-se dizer que a QV é um conceito multidimensional, formado por vários domínios, e se tornou um instrumento eficaz para conhecer a realidade social e como esta é percebida pelos integrantes de uma comunidade (ALBUQUERQUE et al., 2007). É um conceito subjetivo, que envolve a percepção do indivíduo e da sua posição na vida, na cultura, e do sistema de valores nos quais vive, em relação aos seus objetivos, expectativas e padrões.

Dessa forma, a qualidade de vida de expatriados dependerá da relação social que eles estabelecerão e de como os anfitriões do país de destino irão enxergá-los. Assim, uma família árabe, de acordo com seus costumes tradicionais, entenderia uma mulher brasileira como exemplo de despudor, devido às suas vestimentas e envolvimento em negócios, o que poderia provocar, nesta, um sentimento de inadequação. Isso acontece porque indivíduos pertencentes a um mesmo corpo social identificam-se como iguais ou "irmãos", e os estrangeiros, na maioria das vezes, passam a ser tratados como estranhos (CARIGNATO; PACHECO FILHO, 2002). Machado e Hernandes (2003) afirmam que o indivíduo se constrói através da visão do outro, portanto, o sucesso da interação com a outra cultura e das relações sociais que serão estabelecidas facilitarão significativamente a sensação de bem-estar desses profissionais e de suas famílias.

Apesar de a qualidade de vida global ser distinta da qualidade de vida no trabalho, ambas se influenciam mutuamente, motivo pelo qual as organizações devem se preocupar e cuidar da vida pessoal e profissional dos seus expatriados. 


\section{Graziele Zwielewski \& Suzana da Rosa Tolfo}

\subsection{Qualidade de Vida no Trabalho}

A gestão da qualidade de vida no trabalho (QVT) é o conjunto das ações de uma empresa no sentido de implantar melhorias e inovações gerenciais, tecnológicas e estruturais no ambiente de trabalho (LIMONGI-FRANÇA, 2004). O tema da QVT não é uma preocupação atual, pois desde o início das civilizações o homem busca tornar mais amena a sua luta pela sobrevivência através do trabalho. No contexto deste, é conhecida a influência da remuneração sobre a satisfação dos trabalhadores, e outras definições trazidas por diversos autores (WALTON, 1979) têm um ponto em comum: consideram a QVT como um movimento de reação ao rigor dos métodos tayloristas e, consequentemente, a busca por propiciar maior humanização do trabalho, aumentar o bem-estar dos trabalhadores e sua participação nas decisões referentes ao trabalho. Atualmente, a ênfase em QVT representa, cada vez mais, a substituição do sedentarismo e do estresse por maior equilíbrio entre trabalho e lazer, visando extrapolar os limites das "paredes" das organizações e trabalhar a questão do bem-estar do trabalhador de uma forma mais global (SANT'ANNA; KILIMNIK, 2011).

Existem dois focos principais na gestão da QVT: o primeiro é o movimento individual, ou seja, um olhar para a pessoa, o trabalhador, o "objeto" de QVT. Esse movimento se caracteriza pelo aprofundamento da compreensão do estresse e das doenças associadas às condições do ambiente organizacional. E o segundo movimento, o organizacional, se refere à expansão do conceito de qualidade total, que deixa de se restringir a processos e produtos, para abranger aspectos comportamentais e a satisfação de expectativas individuais, visando a concretização dos resultados organizacionais (LIMONGI-FRANÇA; ARELLANO, 2002). Conforme Limongi-França, Antonio e Schirmeister (2016), a busca pela produtividade é um grande desafio para a gestão de pessoas, neste início de século, e o conjunto de ações, programas e estratégias voltadas à qualidade de vida do trabalhador está alinhado com uma concepção ampla de saúde.

Uma vez transferido para uma cidade, estado ou país diferente, o profissional está exposto a vários fatores socioculturais, psicossociais e familiares que afetam sua saúde e nível de estresse, podendo esta experiência ser, inclusive, emocionalmente traumática para ele. Por isso, a preocupação com as consequências da expatriação na qualidade de vida, sobretudo na qualidade de vida do trabalho, vem sendo uma demanda científica e prática, pois, conhecer a relação entre os dois fenômenos (QVT e expatriação) permite criar ações preventivas visando melhores condições de trabalho e a adaptação do expatriado e de sua família.

REAd | Porto Alegre - Edição 84 - N 2 - Maio / Agosto 2016 - p. 510 - 542 


\section{QUALIDADE DE VIDA NO TRABALHO DE PROFISSIONAIS EXPATRIADOS PARA ÍNDIA E CHINA}

Apesar de os estudos sobre QVT existirem há mais de 30 anos na Europa e Estados Unidos, apenas em 1990 se iniciaram no Brasil, com Limongi-França, Moraes, Goulart, Sant'Anna e Kilimnik, Sampaio, Piccinini e Tolfo, Fernandes, entre outros. Como este trabalho investiga a qualidade de vida no trabalho de profissionais expatriados, buscou-se um modelo de QVT que permitisse relacionar as políticas com as ações na organização e com a possibilidade de desenvolver instrumentos de pesquisa adequados às dúvidas e à realidade da categoria profissional investigada.

Existem diversos autores que conceituam a QVT, mas a intenção desta pesquisa não é abordar todos os diferentes conceitos. Portanto, para o desenvolvimento deste trabalho, foi escolhida a definição de Walton (1979), segundo a qual QVT implica no atendimento de necessidades e aspirações humanas, calcada na ideia de humanização organizacional e responsabilidade social por parte da organização. Walton (1979) buscou conceituar QVT e propôs critérios para sua mensuração. Na visão do autor, para que os cargos se tornem mais produtivos e satisfatórios, deve-se observar os aspectos do bem-estar das pessoas nas suas situações de trabalho.

Além do atendimento às aspirações e necessidades dos trabalhadores, como uma maior participação nos processos decisórios, a QVT foca os aspectos humanos do trabalho e a responsabilidade social da empresa. Walton (1979) preconiza a necessidade de ações pragmáticas para melhorar a qualidade de vida no trabalho, e alguns dos elementos propostos pelo autor permitem, de forma objetiva, uma análise da qualidade de vida dos expatriados, pois também estão presentes na relação destes com o trabalho no exterior, como: compensação justa e adequada, condições de trabalho, oportunidade de uso e desenvolvimento de capacidades, oportunidade de crescimento e segurança, integração social na organização, constitucionalismo, o trabalho e o espaço total de vida, e relevância social da vida no trabalho.

\subsection{Expatriação}

Uma das formas encontradas pelas empresas, atualmente, para desenvolver profissionais globais é o fomento à carreira internacional, já que, durante a mudança para o exterior, eles podem assumir responsabilidades, desafios, desenvolver novas competências, relacionamentos e ideias (TUNG, 1998). O processo de expatriação geralmente representa a atribuição de um profissional para uma subsidiária estrangeira, ou seja, é a transferência do executivo para trabalhar e viver em outro país, em geral 


\section{Graziele Zwielewski \& Suzana da Rosa Tolfo}

acompanhado de sua família, por um período de tempo superior a um ano (MITREV; CULPEPPER, 2012; LIMA; BRAGA, 2010).

Esse é o conceito difundido no meio empresarial, mas, em sua raiz etimológica latina, ser expatriado significa estar "fora da sua pátria", ou seja, refere-se a todos os indivíduos que residem temporária ou permanentemente em um país distinto daquele em que nasceram, estando eles vinculados ou não a uma organização (GONZÁLEZ; OLIVEIRA, 2011). Assim, pode-se confundir um pouco este conceito com o de imigrantes, as pessoas que deixam seus países por causas econômicas, porém, não vinculadas a uma transferência profissional através de uma empresa. Como o objetivo deste trabalho é compreender a percepção de expatriados no seu contexto laboral, as definições que seguem compõem o referencial teórico escolhido para definir e conceituar expatriação, e todas elas fazem parte do olhar das pesquisadoras para o fenômeno.

Primeiramente, define-se expatriação como um processo de transferência de um profissional de uma empresa sediada em um determinado país, para trabalhar, por tempo determinado ou não, em uma unidade desta empresa, ou grupo, localizada em outro país. A experiência envolve o indivíduo e sua família de maneira intensa e mobiliza fortemente suas energias emocionais, cria expectativas e coloca-o frente a situações com as quais ele e sua família talvez não estejam preparados para lidar (FREITAS, 2001, p. 20). Tung (1988) e Bueno e Corso (2004) afirmam que a expatriação tem etapas, que vão desde o recrutamento e seleção de candidatos a cargos no exterior, até sua inserção e acompanhamento no novo ambiente organizacional, passando por negociação de benefícios, trâmites legais, alojamento, preparação cultural e de idioma. Na maioria das vezes, é exigido que o profissional se adapte rapidamente à realidade cultural do local anfitrião. Para Gallon et al. (2013), por exemplo, a expatriação tem três etapas: a preparação para a missão, a missão em si e a volta da missão, podendo o retorno ser para o seu país de origem ou para outro país, onde o profissional iniciará uma nova missão. No entanto, Bueno e Corso (2004) e Forster (2000) consideram outro indicador como o fim da expatriação: a repatriação, ou seja, o retorno do expatriado para seu país de origem. Cabe observar que não existe consenso na literatura sobre essas etapas, e o conceito de expatriação é usado para todos os momentos da missão.

Autores também divergem em relação ao tempo mínimo exigido para se caracterizar a expatriação. Para Dutra (2002), ela se concretiza quando o sujeito assume um cargo pela empresa em um país estrangeiro pelo período de um ano; já para Caligiuri (2000), esse período precisa ser de no mínimo dois anos.

REAd | Porto Alegre - Edição 84 - N 2 - Maio / Agosto 2016 - p. 510 - 542 


\section{QUALIDADE DE VIDA NO TRABALHO DE PROFISSIONAIS EXPATRIADOS PARA ÍNDIA E CHINA}

Conforme Dutra (2002), a expatriação é um processo dispendioso, que precisa ser entendido pelas organizações como um projeto em que as futuras relações do expatriado com a nova localidade sejam previamente planejadas e trabalhadas. A necessidade de planejar a expatriação é cada vez mais evidente, pois pesquisas mostram que muitos trabalhadores não se adaptam às suas atividades profissionais no exterior. Na década de 1980, por exemplo, Tung (1981) traz dados de que até $40 \%$ dos executivos americanos expatriados retornavam de suas "missões" mais cedo do que o previsto. Esse número era muito preocupante, já que os custos diretos da expatriação malsucedida ultrapassavam um milhão de dólares e, somados aos custos indiretos anuais decorrentes de um processo de repatriação prematura, chegavam a dois bilhões de dólares por profissional (PEREIRA et al. 2004; ABBOTT et al., 2006). No entanto, todos os autores parecem concordar em que o contato com outra cultura submete o profissional a algumas perdas e pode abalar sua autoestima, pelo fato de este se sentir incapaz de lidar com situações aparentemente banais, mas essenciais à sua sobrevivência. Para ele, ser expatriado significa alterar suas rotinas e construir nova rede de relacionamentos, já que a empresa o insere em um contexto cultural diferente do seu, na maioria das vezes longe da sua família, dos amigos e com responsabilidades aumentadas (LACOMBE, 2004).

A prática de internacionalizar pessoas é um desafio para departamentos de gestão de pessoas, pois estes precisam oferecer apoio a esses profissionais durante todo o processo de expatriação. Este apoio contribui para reter o profissional durante o processo e também para o sucesso da expatriação na ida e na volta do indivíduo, em termos pessoais, profissionais, organizacionais, sociais e culturais (LIMA; BRAGA, 2010).

Mesmo implicando em desafios, a expatriação se torna importante estratégia para a organização, pois permite propagar a cultura organizacional, homogeneizar linguagens, construir oportunidades e desenvolvimento de carreira internacional para os profissionais essenciais para a organização, além de possibilitar sua interação com novos conhecimentos. A expatriação influencia também nos ganhos financeiros, geralmente de forma positiva, pois os planos de carreira preveem aumento salarial e de benefícios para profissionais expatriados. Em etapas históricas anteriores, esse crescimento econômico era considerado uma evidência de QVT, mas hoje, sabe-se que qualidade de vida no trabalho não se restringe à remuneração.

Outra problemática que influencia nos aspectos socioculturais e psicossociais da expatriação é a relação de liderança estabelecida entre brasileiros expatriados e sua equipe de trabalho. Homem (2005) apresenta os relatos de um dos expatriados e da administradora dos expatriados da empresa Racional, 


\section{Graziele Zwielewski \& Suzana da Rosa Tolfo}

sediada no estado de Santa Catarina, segundo os quais, italianos tinham dificuldade de aceitar a posição hierárquica superior e as ideias de brasileiros expatriados, por considerá-los profissionais de terceiro mundo. Essa situação, além de impactar na autoestima do expatriado, pode prejudicar sua adaptação ao país anfitrião e seu relacionamento com colegas de trabalho, afetando significativamente seu desempenho profissional e suas chances de permanecer no exterior.

Ser expatriado, para os profissionais, significa deixar suas condições familiares, interromper rotinas, sofrer com incertezas e demandas por ajustamentos em curto espaço de tempo. Essas condições podem gerar o fenômeno definido por Hofstede (2001) como choque cultural, que pode surgir a partir do momento em que um indivíduo sai do seu país e se insere em outro, com hábitos, tradições e, principalmente, padrões culturais que diferem dos seus. Diante dessas mudanças, ele pode sofrer desajuste emocional, na tentativa de se adaptar ao novo contexto, o que caracteriza o choque cultural. $\mathrm{O}$ sujeito também muda características pessoais durante a experiência internacional, pois, através de um processo chamado por Berry (2004) de aculturação, sua identidade é redefinida, sua visão de mundo e valores se modificam e podem se tornar incompatíveis aos valores e visão de mundo da sua família e da cultura da organização de origem (TUNG, 1988). Além disso, podem ocorrer mudanças organizacionais durante a expatriação, como reestruturações e mudanças de estratégia.

Para Berry (2004), o sujeito pode lidar com a experiência internacional de quatro formas: a primeira, quando ele não faz questão de manter sua herança cultural, e assimila a cultura anfitriã enquanto interage com ela. A segunda forma é quando a manutenção da cultura de origem é importante para o sujeito, e ele passa a evitar a interação com a cultura local, o que o autor chama de separação. A terceira forma, a integração, ocorre quando o sujeito tem interesse em manter sua cultura de origem, mas também interage com grupos da cultura anfitriã; e por último, o comportamento contrário, quando não existe interesse em manter a cultura de origem, nem existe interação com a cultura local, e isso implica na marginalização do indivíduo.

Sendo assim, é necessário considerar que qualquer experiência vivenciada pelo ser humano no contexto sociocultural em que está inserido afetará, de forma significativa, seu estado afetivo, emocional e cognitivo (KANAANE, 1999). Ainda mais ao se tratar de uma expatriação, em que o profissional leva consigo seus costumes, idioma, religião, opiniões políticas, e se depara, conforme afirma Ramos (2004), com a necessidade de flexibilizar o "seu eu", para se adaptar às regras e costumes locais.

REAd | Porto Alegre - Edição 84 - N 2 - Maio / Agosto 2016 - p. 510 - 542 


\section{QUALIDADE DE VIDA NO TRABALHO DE PROFISSIONAIS EXPATRIADOS PARA ÍNDIA E CHINA}

Para que esses problemas sejam minimizados, o Departamento de Gestão Internacional de Pessoas da empresa deve considerar as fases de adaptação cultural que o expatriado vivenciará, para the dar os devidos suportes. Estas fases são quatro, e a primeira delas é identificada como "lua de mel" ou "fase do encantamento" (BLACK; MENDENHALL; ODDOU, 1991). Para Joly (1996), esta se caracteriza pela fascinação que a cultura anfitriã proporciona ao expatriado, por ser tudo novidade para ele. À medida que o sujeito vivencia as primeiras dificuldades e precisa lidar com a realidade do novo local, ele começa a vivenciar a segunda fase, a de "choque cultural", ou "negativismo", caracterizada como momentos de ansiedade e medo de perder os sinais e símbolos que the são familiares socialmente. Quando o expatriado consegue finalmente superar essa fase traumática, ele vivencia um período de ajuste, de "adaptação", que é a terceira fase, quando, aos poucos, aprende novas formas de interpretar sua realidade, desenvolve novos padrões de comportamento e começa a se integrar ou a rejeitar definitivamente a nova cultura. Por fim, o sujeito alcança o "domínio" cultural, que é a quarta e última fase (BLACK; MENDENHALL; ODDOU, 1991; JOLY, 1996).

Em estudo desenvolvido em Taiwan, Chen e Chui (2009) verificaram que a precepção de expatriados quanto ao cumprimento dos contratos psicológicos influencia significativamente a sua adaptação às situações estrangeiras e seu comprometimento organizacional. Barreiras psicológicas para o ajuste têm uma influência negativa nos ajustamentos sociocultural e psicológico. Na prática, os gestores internacionais devem implementar medidas de gestão adequadas para satisfazer as expectativas dos expatriados em relação a seus contratos psicológicos. Os gestores devem garantir que os expatriados recebam conselhos e formação adequados, para ajudá-los a minimizar quaisquer barreiras psicológicas que possam ter no ajustamento a um ambiente externo (CHEN; CHUI 2009).

$\mathrm{Na}$ literatura pesquisada, foram encontrados dados que levam a concluir que a missão obtém sucesso quando todas as fases são vivenciadas sem que ela sofra interrupções, ainda que estas não sejam totalmente superadas. Porém, pesquisas têm indicado que de 20 a 40 por cento dos expatriados não fazem uma boa transição e retornam mais cedo ao país de origem (BAKER; IVANCEVICK, 1971; BLACK, 1988; TUNG, 1981). Em suma, percebe-se que o processo de expatriação e suas etapas vêm demandando uma atenção maior por parte das empresas, porém, nem todas as empresas que enviam profissionais ao exterior possuem atualmente um departamento específico para administração de expatriados.

Em resumo, a insatisfação com a vida no trabalho afeta a maioria dos trabalhadores em alguma fase da sua vida profissional, independente de sua posição hierárquica ou status, como afirma Walton 


\section{Graziele Zwielewski \& Suzana da Rosa Tolfo}

(1979). Porém, ainda que haja aspectos positivos na expatriação, vários são os fatores (socioculturais, psicossociais e familiares) que afetam a saúde, o nível de estresse e a qualidade de vida dos expatriados, podendo esse processo ser até traumatizante para eles (FRANKEN; COUTINHO; RAMOS, 2007).

\section{MÉTODO DE PESQUISA}

Este artigo apresenta resultados de uma dissertação de mestrado, que abordou os fenômenos qualidade de vida no trabalho e expatriação. Foi privilegiada uma perspectiva teórico-metodológicaqualitativa, que busca compreender o significado atribuído pelas pessoas a um determinado fenômeno, identificando a realidade socialmente construída por meio desses significados, sem buscar, no entanto, a quantificação, intensidade ou frequência de dados (LAVILLE; DIONE, 1999). Dessa forma, foram entrevistados cinco expatriados para a Índia e cinco expatriados para a China, que são empregados de uma indústria de carrocerias de ônibus do sul do Brasil.

O lócus da pesquisa foi, então, uma indústria gaúcha, à qual se deu o codinome de Ind. M., e que possuía, à época, 82 funcionários expatriados, alocados nos seguintes países: Argentina, Colômbia, México, Egito, África do Sul, Rússia, China e Índia. Considerando-se a afirmação de Kubo (2011), para quem o ajustamento intercultural atua como elemento central no sucesso da expatriação, ou seja, no não retorno antecipado do expatriado, buscou-se selecionar, como sujeitos da pesquisa, profissionais expatriados em países orientais, já que a cultura daqueles países apresenta maior distanciamento da cultura brasileira, no pressuposto de que quanto maiores forem as diferenças culturais, maiores serão as dificuldades do expatriado em se adaptar ao país anfitrião. Dentre as unidades orientais da Ind.M., foram escolhidas as da China e Índia, devido ao maior tempo de funcionamento e maior número de expatriados.

Na pesquisa, utilizou-se o método de estudo de caso, que, conforme Eisenhardt (1989), procura entender profundamente a dinâmica presente nos cenários particulares. $O$ estudo de caso pode ser usado para atingir vários objetivos, dentre eles, dar uma descrição, testar ou criar teorias. Como uma estratégia de pesquisa, os estudos de caso permitem que o pesquisador tenha uma visão holística e de significados sobre as situações de vida reais dos sujeitos.

A busca das informações necessárias a esta pesquisa foi feita por meio de entrevistas com os expatriados e com a gestora do departamento de expatriados (fontes primárias), e também por análise 


\section{QUALIDADE DE VIDA NO TRABALHO DE PROFISSIONAIS EXPATRIADOS PARA ÍNDIA E CHINA}

de documentos da empresa pesquisada (fonte secundária). Para esta pesquisa, foram analisados três documentos fornecidos pelo Departamento de Expatriados da Ind. M.: a Política de Expatriação, onde estão descritas as regras, normas e procedimentos para expatriar um funcionário; a Política de Remuneração e Carreira, que define os retornos financeiros e contrapartidas pela contribuição prestada pelo expatriado, assim como itens importantes para a gestão da carreira; e o Pacto Acessório, um contrato assinado entre empresa e expatriado, com itens não contemplados nos documentos anteriores.

Para a realização das entrevistas foi solicitado ao departamento de Recursos Humanos da Ind. M. o endereço eletrônico dos expatriados. Em seguida, enviou-se mensagem convidando-os a participarem da pesquisa. Quando o expatriado aceitava participar, eram atendidas as questões éticas (CEPSH) e agendava-se uma entrevista com ele, feita pelo Skype, com duração média de duas horas cada.

Para tratamento das informações coletadas na unidade de análise "indivíduo", fez-se a transcrição das entrevistas realizadas com os funcionários e, através da análise de conteúdo dessas transcrições, foi possível transcender o significado do material transcrito, compreendendo-se o sentido do discurso dos entrevistados (GODIM; FISCHER, 2009).

Com relação à unidade de análise “organização”, fez-se a análise de conteúdo da entrevista com a gerência do departamento de expatriados e dos documentos fornecidos pela empresa. Essas duas formas de análise possuem técnicas semelhantes, ambas utilizadas pelas autoras: a codificação das informações após a identificação dos sujeitos e o estabelecimento de categorias principais. As informações coletadas por meio da análise de documentos foram inicialmente registradas em um protocolo de registro de informações e posteriormente foram agrupadas e categorizadas de acordo com a base teórica adotada.

\section{ANÁLISE DOS RESULTADOS}

Com base na análise dos documentos, verificou-se que a Ind. M. não possui claramente definidos os termos expatriação e expatriado: este é considerado apenas um profissional transferido para outras unidades da empresa, e expatriação é considerada uma situação momentânea da carreira do profissional, sem caráter definitivo. Já a gestora do departamento responsável pela expatriação, chamada neste trabalho de M., define expatriação como: "transferência de um colaborador para o exterior por um período maior de dois anos” (M.). Também não foram encontradas, em qualquer 


\section{Graziele Zwielewski \& Suzana da Rosa Tolfo}

documento da empresa, definições a respeito de expatriação ou do sucesso desta; apenas observou-se que, ocorrendo o desligamento por iniciativa do expatriado, este arcará com as despesas de retorno. No entanto, percebe-se alguns princípios que norteiam as políticas do departamento de expatriação, como na Política de Expatriados e no Pacto Acessório, que fazem menção aos "benefícios financeiros", valorando-os com um acréscimo de $25 \%$ enquanto o profissional estiver expatriado, além de prever o custeio de despesas com acomodação, alimentação, transporte para expatriados não acompanhados da família; e ressarcimento da educação dos filhos, além de casa mobiliada, para expatriados acompanhados de suas famílias. Esses princípios também norteiam as empresas empregadoras dos expatriados entrevistados por Tissot et al. (2014), que relatam receber da empresa um aumento de $15 \%$ a $20 \%$ do salário, um valor de diária, além de custos com hotel e motorista, embora estes fossem benefícios mais amplos. Nesse mesmo estudo, os expatriados relatam que, em cargos gerenciais, as horas extras são contabilizadas, os profissionais recebem auxílio-moradia e escola para os filhos, além de viagens anuais para o Brasil.

\subsection{Qualidade de vida no trabalho na percepção dos expatriados}

Os resultados da coleta e análise dos dados foram listados no quadro 1, para sua melhor visualização, onde as linhas horizontais apresentam os oito elementos propostos por Walton (1979) como importantes para a QVT, e as colunas listam as evidências da presença e ausência de determinados elementos na expatriação promovida pela Ind. M.

Quadro 1 - Os oito indicadores de Walton e evidências de QVT na percepção dos expatriados

\begin{tabular}{|l|l|l|}
\hline \multicolumn{1}{|c|}{$\begin{array}{c}\text { Indicadores de } \\
\text { QVT }\end{array}$} & \multicolumn{1}{c|}{ Evidências a favor } & \multicolumn{1}{c|}{ Evidências contrárias } \\
\hline $\begin{array}{l}\text { Condição do } \\
\text { trabalho }\end{array}$ & $\begin{array}{l}\text { - Os supervisores consideram ter } \\
\text { os recursos necessários, } \\
\text { inclusive uma tradutora. }\end{array}$ & $\begin{array}{l}\text { - Falta de água, ar condicionado adequado, } \\
\text { dependem de um carro para se deslocar na } \\
\text { fábrica, falta de cadeiras, espaço físico, } \\
\text { banheiros, papel higiênico; } \\
\text { - necessidade de usar pertences pessoais no } \\
\text { trabalho, como o laptop, internet; } \\
\text { - os chineses cospem o tempo todo e fumam } \\
\text { demais, inclusive em reuniões de trabalho. }\end{array}$ \\
\hline $\begin{array}{l}\text { Oportunidade de } \\
\text { uso e } \\
\text { desenvolvimento de }\end{array}$ & $\begin{array}{l}\text { - A expatriação favorece o } \\
\text { aprendizado e o } \\
\text { desenvolvimento de novas }\end{array}$ & $\begin{array}{l}\text { - O aprendizado técnico-operacional adquirido } \\
\text { nos dois países foi negativo, e os expatriados } \\
\text { se consideram desatualizados e com }\end{array}$ \\
\hline
\end{tabular}

REAd | Porto Alegre - Edição 84 - № 2 - Maio / Agosto 2016 - p. 510 - 542 
QUALIDADE DE VIDA NO TRABALHO DE PROFISSIONAIS EXPATRIADOS PARA ÍNDIA E CHINA

\begin{tabular}{|c|c|c|}
\hline habilidades & $\begin{array}{l}\text { habilidades, como as citadas no } \\
\text { corpo deste trabalho. }\end{array}$ & $\begin{array}{l}\text { conhecimento defasado para voltar a trabalhar } \\
\text { na fábrica, no Brasil; } \\
\text { - a empresa não ajuda com pagamento de um } \\
\text { curso de idioma; } \\
\text { - muitas das habilidades e conhecimentos } \\
\text { adquiridos não são aproveitados após a } \\
\text { expatriação. }\end{array}$ \\
\hline $\begin{array}{l}\text { Compensação justa } \\
\text { e adequada }\end{array}$ & - Ter um salário justo e adequado. & \\
\hline Integração social & $\begin{array}{l}\text { - Cordialidade no ambiente de } \\
\text { trabalho. }\end{array}$ & $\begin{array}{l}\text { - Pouca integração social com os locais; } \\
\text { - três dos expatriados consideram ter relação de } \\
\text { respeito com os profissionais locais, mas } \\
\text { poderia melhorar: os chineses fumam e } \\
\text { cospem demais; os indianos são } \\
\text { desorganizados e precisam ouvir sempre as } \\
\text { instruções, em vez de fazer. }\end{array}$ \\
\hline $\begin{array}{l}\text { Oportunidade de } \\
\text { crescimento e } \\
\text { segurança }\end{array}$ & - É uma experiência internacional. & $\begin{array}{l}\text { - Ausência de um plano de carreira; } \\
\text { - insegurança do contrato trimestral; } \\
\text { - dois dos expatriados deixaram seus estudos no } \\
\text { Brasil, para serem expatriados, e não sabem } \\
\text { avaliar se isso valeu a pena; } \\
\text { - casos de expatriados anteriores que voltaram e } \\
\text { não colocaram em prática o conhecimento e a } \\
\text { experiência aprendida durante a expatriação; } \\
\text { - repatriados que assumiram seus antigos cargos, } \\
\text { não sendo a expatriação uma oportunidade de } \\
\text { crescimento hierárquico na empresa. }\end{array}$ \\
\hline Constituciona-lismo & $\begin{array}{l}\text { - Salário compatível com a } \\
\text { expectativa; } \\
\text { - água diferenciada; } \\
\text { - horário e transporte } \\
\text { diferenciado; } \\
\text { - liberdade para entrar e sair da } \\
\text { fábrica. }\end{array}$ & $\begin{array}{l}\text { - Na Índia, os expatriados relatam falta de } \\
\text { privacidade por morarem em duplas, no hotel. }\end{array}$ \\
\hline $\begin{array}{l}\text { Trabalho e espaço } \\
\text { total na vida }\end{array}$ & $\begin{array}{l}\text { - Sair para jantar com outros } \\
\text { brasileiros expatriados. }\end{array}$ & $\begin{array}{l}\text { - Distância da família e privação do convívio na } \\
\text { maioria dos casos (oito dos dez entrevistados); } \\
\text { - carga horária muito alta; } \\
\text { - frequentemente não possuem finais de semana } \\
\text { para descansar; } \\
\text { - o fuso horário dificulta o contato diário com a } \\
\text { família que está no Brasil; } \\
\text { - não possuem atividades de lazer frequentes; } \\
\text { - não exercem atividades cívicas. }\end{array}$ \\
\hline Relevância social da & - O conhecimento passado para os & \\
\hline
\end{tabular}

REAd | Porto Alegre - Edição 84 - № 2 - Maio / Agosto 2016 - p. 510 - 542 


\section{Graziele Zwielewski \& Suzana da Rosa Tolfo}

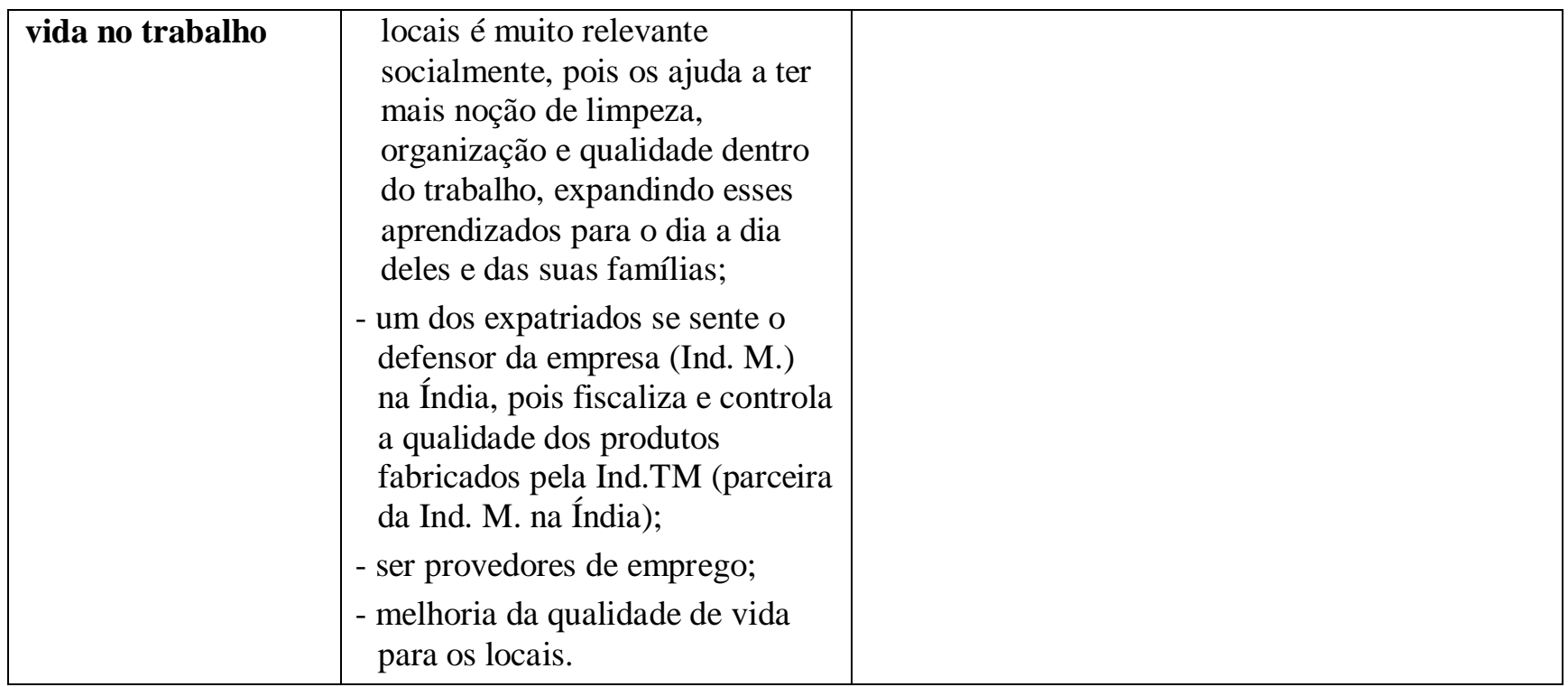

Fonte: As autoras (2014).

Considerando os oito indicadores de Walton (1979), a Ind. M. contempla alguns aspectos em todos os itens (conforme a figura 1, mais adiante), porém, a maioria deles de maneira limitada, e apenas três são suficientemente contemplados: a compensação justa e adequada, o constitucionalismo e a relevância social da vida no trabalho, como apontado no quadro 1. Os indicadores não contemplados de forma satisfatória pela empresa são cinco:

a) condições no trabalho: a estrutura física e material, assim como o ambiente físico encontrados são considerados insuficientes para os expatriados, apesar de estes reconhecerem que essas condições já foram piores;

b) oportunidade de uso e desenvolvimento de habilidades: os expatriados se sentem com conhecimentos defasados, pois não consideram aproveitável o conhecimento adquirido, uma vez que a tecnologia utilizada e a morosidade nos dois países não são formas adequadas de trabalho;

c) integração social: apesar de haver respeito entre brasileiros e profissionais locais, em ambos os países, os expatriados relatam ter pouca atividade social junto com indianos e chineses, devido a dificuldades de comunicação, diferenças culturais de comportamento e formas de resolver problemas relacionados a essa diferença cultural. Porém, realizam atividades com brasileiros da mesma empresa; 


\section{QUALIDADE DE VIDA NO TRABALHO DE PROFISSIONAIS EXPATRIADOS PARA ÍNDIA E CHINA}

d) oportunidade de crescimento e segurança: percebeu-se ansiedade nos entrevistados com relação à carreira e planos futuros: falta um plano de carreira e orientação para o desenvolvimento de habilidades a serem utilizadas futuramente;

e) trabalho e espaço total na vida: além do trabalho, as outras atividades dos expatriados são permanecer no hotel com os colegas brasileiros e sair com eles para jantar.

Os oito expatriados privados da convivência familiar não dispõem do final de semana para descansar, pois trabalham mais de dez dias seguidos; nem dispõem de atividades de lazer ou atividades cívicas, todas elas consideradas por Walton (1979) como essenciais para a QVT. Diferentes aspectos poderiam ser encontrados, caso os expatriados estivessem em outro país, porém, acredita-se que a ausência do elemento "trabalho e espaço total na vida" foi reforçada devido à diferença cultural do país onde os expatriados se encontram e, por essa razão, pode-se compreender os motivos pelos quais a família não os acompanhou. Os outros dois expatriados, que estão com suas famílias, conseguem fazer atividades com esposa e filhos, o que é essencial para uma expatriação de sucesso, tanto para o expatriado quanto para a organização (VAN ERP et al., 2009), porém, assim como os demais expatriados, consideram a carga horária de trabalho alta, apontada por Grant-Vallone e Ensher (2001) como um interveniente negativo na percepção de bem-estar dos expatriados e suas famílias. Esta pode ser um tipo de situação que leva os expatriados a sentimentos de desajuste, mas que nem sempre implica em rescindir os seus trabalhos transculturais. Mesmo com dificuldades de se ajustar à cultura hospedeira, a maioria permanece no exterior devido ao temor dos efeitos negativos do retorno prematuro, especialmente para aqueles voltados ao desenvolvimento global da carreira (BENSON, 1978).

Apesar de os argumentos citados serem suficientes para concluir que a Ind. M. poderia ampliar suas estratégias para buscar melhor qualidade de vida no trabalho dos expatriados, outro elemento foi observado como essencial para tanto: a adaptação cultural, entendida como a construção de novas rotinas e novo ambiente social, familiar e profissional, em que ajustes precisam ser feitos para reduzir a sensação de mal-estar advinda da diferença cultural (FREITAS, 2010). Para Lee e Van Horst (2010), a adaptação transcultural é relativa ao conforto que o profissional vivencia em relação a diversos aspectos ligados à vida e ao trabalho no exterior. Para expatriados, a adaptação transcultural entendida como um processo ajuda a reduzir o desconforto frequentemente vivenciado em uma nova cultura e facilita que o seu cotidiano seja mais harmonioso (PELTOKORPI; FROESE, 2009; BLACK, 1988). 


\section{Graziele Zwielewski \& Suzana da Rosa Tolfo}

Observou-se que muitos dos problemas citados pelos expatriados, e que comprometem elementos importantes para a QVT, são de origem cultural, relacionando-se à falta de compreensão da cultura em que os profissionais foram inseridos e à falta de preparação intercultural destes e de suas famílias: problemas de socialização, comunicação, transporte, lazer; ambiente de trabalho (água, temperatura, comportamentos estranhos como cuspir e fumar); banheiro inadequado ou inexistente, falta do papel higiênico; falta de compreensão de alguns comportamentos da equipe; alimentação diferente e problemas com saúde emocional e física da família. Conforme Wang (2002), essa distância cultural, apresentada no dia a dia dos expatriados, está negativamente relacionada com a adaptação e o ajustamento cultural, mas, por outro lado, o suporte organizacional pode oferecer uma relação positiva com o ajustamento intercultural. Considerando a China, Chen e Chui (2009) salientam a importância dos contratos psicológicos e o seu cumprimento para a adaptação ao estrangeiro e para o comprometimento organizacional, pois barreiras psicológicas influenciam negativamente no ajuste sociocultural e no ajustamento psicológico. A seleção de profissionais para as vagas de expatriados, com características como extroversão, estabilidade emocional, sensibilidade cultural, maior capacidade de linguagem local, flexibilidade cultura, tolerância a ambiguidades, também colabora com o ajustamento intercultural dos expatriados (MOL et al., 2005).

Tendo em vista o exposto, ao se utilizar os oito elementos propostos por Walton (1979) para avaliar a qualidade de vida no trabalho de expatriados, é necessário considerar as diferenças culturais existentes entre os países envolvidos no processo da expatriação, além de acrescentar dois novos elementos nesta avaliação: sentidos do trabalho e adaptação cultural (integração social intercultural, cuidados com a família e comunicação intercultural), explicados a seguir. Nesse sentido, a proposição de um novo desenho pode ser observada na figura 1.

Figura 1 - Elementos para avaliação da qualidade de vida no trabalho para profissionais expatriados

REAd | Porto Alegre - Edição 84 - № 2 - Maio / Agosto 2016 - p. 510 - 542 
QUALIDADE DE VIDA NO TRABALHO DE PROFISSIONAIS EXPATRIADOS PARA ÍNDIA E CHINA

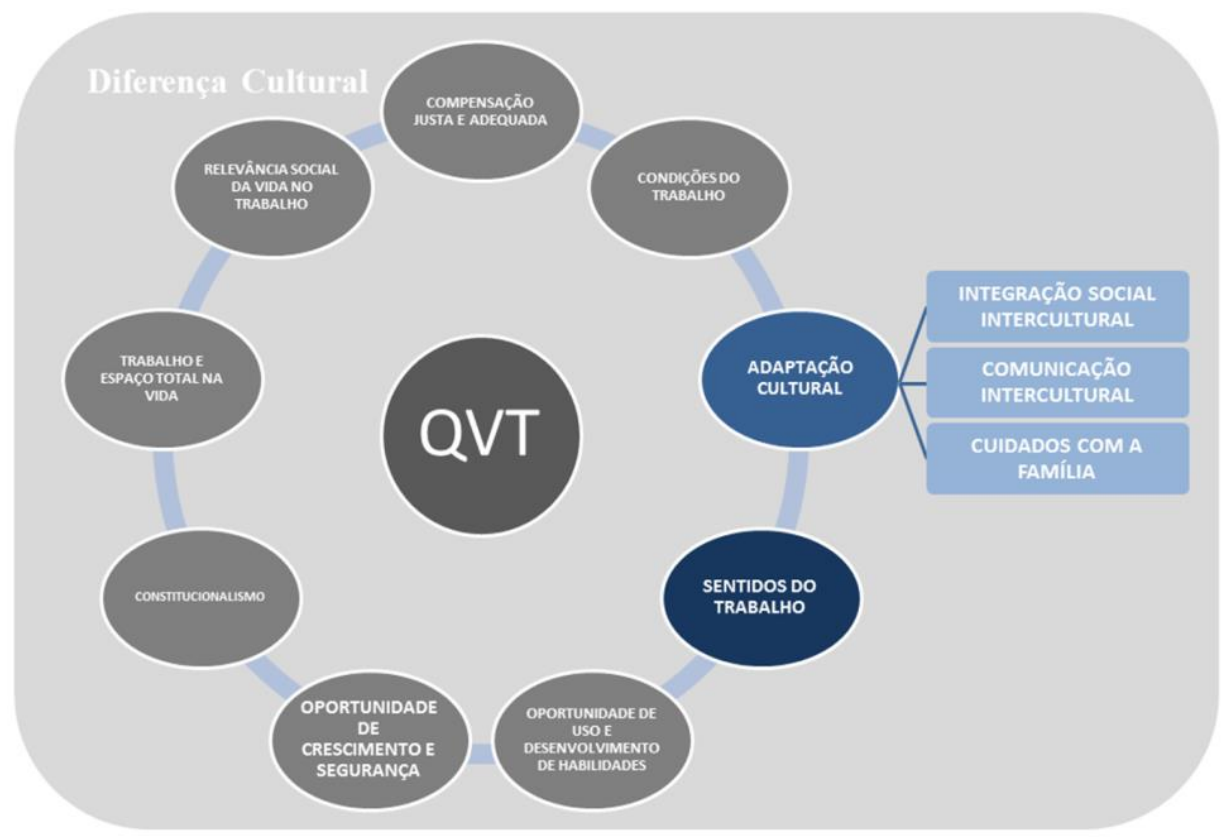

Fonte: Adaptado de Walton (1979), pela autora principal.

A modificação e adaptação propostas para a avaliação da qualidade de vida dos expatriados busca complementar o proposto anteriormente por Walton (1979) e adaptá-lo para avaliação da QVT em profissionais que trabalham fora do seu contexto cultural.

No elemento oportunidade de uso e desenvolvimento de habilidades, avaliar e desenvolver a habilidade intercultural antes de o profissional ser expatriado é essencial para que este possa compreender diferenças culturais em seus colegas de trabalho, nos procedimentos da empresa, podendo desenvolver a habilidade de se relacionar e até gerir pessoas de diferentes culturas. Para Van der Zee e Van Oudenhoven (2013), traços de personalidade como a estabilidade emocional e a flexibilidade estão ligados a uma menor tendência a interpretar uma situação intercultural como ameaçadora. Com relação ao elemento oportunidade de crescimento e segurança, a empresa precisa criar planos de carreira considerando oportunidades em nível global, aproveitando a habilidade intercultural desenvolvida pelo profissional. Oferecer um tutor que já tenha passado pela experiência da expatriação ajuda o expatriado a se ambientar ao novo país e cultura, e compreender o que se espera dele como profissional e também como lidar com a equipe local. Programas de tutoria possibilitam que a empresa coloque antigos expatriados para acompanhar novos expatriados, garantindo que os mais experientes aproveitem as habilidades interculturais desenvolvidas durante a sua expatriação, para ajudar os novos expatriados. 


\section{Graziele Zwielewski \& Suzana da Rosa Tolfo}

Com relação às condições de trabalho consideradas por Walton (1979), é importante que os RHs (de origem e o anfitrião) se comuniquem, para identificar possíveis diferenças no ambiente de trabalho que possam prejudicar o bem-estar do expatriado e dificultar sua adaptação cultural, como, por exemplo: a falta de cadeiras na empresa indiana por questões culturais (os indianos não trabalham sentados e sim agachados) poderia ter sido evitada. O sentido do trabalho, citado por Sampaio (2012) e Morin (2001) como elemento também relevante para a avaliação da qualidade de vida no trabalho, apareceu nos resultados desta pesquisa como elemento importante, pois, para o expatriado, entender os motivos que o fizeram aceitar a missão ajuda-o a lidar com os desafios que enfrenta no seu dia a dia, tornando seu trabalho aceitável moralmente, ainda que com muitas dificuldades, pois ele sabe que com esta atividade conseguirá alcançar o objetivo determinado.

A adaptação cultural do expatriado está relacionada ao bem-estar do profissional no seu ambiente de trabalho, mas também depende da sua adaptação no ambiente familiar e social. A família, como já citado, é fundamental na adaptação do expatriado e, consequentemente, no aumento da sua capacidade produtiva. Expatriados mal-adaptados tendem a se mostrar insatisfeitos com o trabalho (SHAY; BAACK, 2006) e apresentar desempenhos menos satisfatórios (SHIH; CHIANGHSU, 2010). Além disso, em situações mais extremas, podem retornar prematuramente do exterior ou enfrentar uma demissão (RAMALU et al., 2010).

Dessa forma, considerando a importância do meio social e da família na adaptação cultural, propõe-se a inserção de três conceitos subordinados à adaptação cultural, considerados essenciais para análise da QVT: integração social intercultural, cuidados com a família e comunicação intercultural.

A integração social, proposta por Walton (1979), é elemento importante para a QVT do trabalhador, porém, para profissionais expatriados, com ou sem a família, a vida social é ainda mais importante, pois todas as relações sociais do expatriado e de sua família foram deixadas no país de origem. Assim, uma nova rede de relações precisa ser criada, considerando as diferenças culturais, de idioma e de interesses. Criar vínculos torna-se difícil, uma vez que o novo profissional não é conhecido no país anfitrião e precisará passar credibilidade, para gerar confiança às relações que fizer. Em função dessa necessidade de integração social e de criação de novas relações, propõe-se que o elemento integração social seja complementado pela palavra intercultural, aparecendo, portanto, como integração social intercultural.

Em relação aos cuidados com a família, caso esta não esteja expatriada, um dos entrevistados (Ken) comentou o quão importante seria se a empresa entrasse em contato com seu filho, pelo menos 


\section{QUALIDADE DE VIDA NO TRABALHO DE PROFISSIONAIS EXPATRIADOS PARA ÍNDIA E CHINA}

por telefone, para lhe passar segurança enquanto o pai está na China, a trabalho. Nesse sentido, a empresa poderá adotar diversas ações para auxiliar a família a compreender a missão em que o expatriado será inserido e se sentir segura diante das mudanças advindas da expatriação.

No caso de a família ser expatriada junto com o profissional, ela precisa ter as suas habilidades interculturais avaliadas e desenvolvidas para melhor se adaptar; receber apoio emocional; auxílio para encontrar escola; casa adequada para seu perfil, considerando escola das crianças, trabalho e locais para lazer. Precisa de vistos adequados, principalmente quando o cônjuge pretende trabalhar (visto de trabalho) ou estudar (visto de estudante). No caso de profissionais mais estratégicos para a empresa, esta também pode se preocupar com reinserção do cônjuge no mercado de trabalho; com a montagem da casa; curso de idioma; apoio à inserção social da família no novo contexto cultural; dar treinamento e orientação sobre a cultura anfitriã; plano de saúde internacional; verbas para assinatura de revistas; orientações para casos de emergência e telefones para serviços básicos. Essas necessidades foram coletadas durante a pesquisa e complementadas de acordo com a pesquisa de Freitas (2010).

Por último, além da integração social intercultural e dos cuidados com a família, um novo elemento é proposto: a comunicação intercultural. Canais de comunicação entre o país de origem e o de destino precisam ser criados, como sugerido pelos próprios expatriados. Orientações precisam ser oferecidas sobre como lidar com a equipe local considerando as dificuldades de comunicação advindas da diferença de idioma, pronúncias e orientações sobre a comunicação não verbal como, por exemplo, sobre os comportamentos permissíveis e não permissíveis. A empresa precisa oferecer cursos de idioma e orientações sobre como se expressar nesse outro idioma, pois muitas palavras, se traduzidas ao pé da letra, não são adequadas para serem usadas no outro país. Além disso, a empresa deve atentar para a dificuldade do expatriado não apenas em conversar no novo idioma, mas também em expressar seus sentimentos e desejos, conforme citado pelos entrevistados.

Conclui-se que, ao se aplicar os elementos de Walton (1979) adaptados à diferença cultural, considerando os sentidos do trabalho e a importância da adaptação cultural do profissional, esta última dependente dos três novos conceitos propostos - comunicação intercultural, integração social intercultural e cuidado com a família -, os expatriados e suas famílias poderão passar pelas fases de adaptação de forma mais harmônica, sem perder qualidade de vida e conseguindo atingir a última fase da adaptação, o entusiasmo, o que, consequentemente, se reverterá em maior disponibilidade do profissional para o trabalho e saúde em um sentido amplo (LIMONGI-FRANÇA; ANTONIO; SCHIRMEISTER, 2016). 


\section{Graziele Zwielewski \& Suzana da Rosa Tolfo}

\section{CONSIDERAÇÕES FINAIS}

Para os entrevistados, a expatriação é uma oportunidade de crescimento profissional, um desafio e um ato de reconhecimento da empresa pelo trabalho realizado pelo futuro expatriado, até o momento do convite. Isto porque a Ind. M., apesar de realizar expatriações desde 2000, ainda não definiu políticas e procedimentos para nortear a transferência desses profissionais, como sugerido pela teoria apresentada neste trabalho (processo seletivo para avaliação de competências interculturais, treinamento e desenvolvimento dessas habilidades, visita ao país de destino, programa de tutoria, programas de apoio à família, plano de carreira para expatriados, iniciativas para integração social do expatriado, entre outros).

Alguns expatriados relatam ter qualidade de vida no trabalho, ainda que tenham problemas no ambiente físico. Um dos expatriados relata sofrer muita pressão, por parte dos chineses, para não cometer erros, e um membro de sua família expatriada teve problemas graves de saúde, mas, mesmo assim, ele considera ter qualidade de vida no trabalho.

Os profissionais entrevistados, apesar de terem a percepção de que a expatriação lhes oferece oportunidade para crescimento profissional, não se sentem seguros com os possíveis impactos da sua volta ao país de origem, uma vez que não existe, na empresa, planejamento de carreira. No retorno, eles se sentem desatualizados, pela falta de treinamento e de informações sobre o que está acontecendo no país de origem, e por terem permanecido distantes da observação pelas chefias no Brasil. Para eles, a expatriação precisa levar em consideração o tempo que será dedicado à missão, pois eles deixam, no país de origem, sonhos e projetos já iniciados, os estudos e a convivência com pessoas queridas, um tempo que jamais conseguirão recuperar.

Um dos expatriados citou, como impacto negativo, o fato de precisar de algumas coisas e de não saber como e onde as buscar, e, inclusive, como persuadir as pessoas de outra cultura. Além disso, há o medo de "incorporar" o comportamento indesejado do estrangeiro (morosidade na execução das atividades laborais, por exemplo) e a sensação de estar esquecido pela empresa do país de origem.

Para redução desses aspectos negativos e para melhorar a percepção dos expatriados sobre a experiência da expatriação, sugere-se algumas iniciativas como: realização de visita experimental, não apenas de reconhecimento, ao país de destino; preparação e desenvolvimento intercultural dos profissionais; um programa de tutoria ou um consultor local; RH anfitrião mais ativo; treinamento no 


\section{QUALIDADE DE VIDA NO TRABALHO DE PROFISSIONAIS EXPATRIADOS PARA ÍNDIA E CHINA}

idioma antes e durante a expatriação; avaliação semestral do desempenho dos expatriados e criação de um informativo keep in touch.

Além disso, também foi sugerido que os oito indicadores propostos por Walton (1979) sejam reavaliados considerando sempre a diferença cultural entre os países envolvidos na expatriação, com a inserção, inclusive, de dois novos elementos importantes para avaliação da QVT de profissionais expatriados: sentidos do trabalho e adaptação cultural (integração social intercultural, comunicação intercultural, cuidados com a família).

Nesse contexto, pode-se ressaltar a importância do papel do psicólogo na orientação e apoio na resolução dos aspectos emocionais ligados à diferença cultural, à perda de identidade, solidão, choque cultural, adaptação, relacionamentos, entre outras dificuldades.

Pôde-se compreender, ao final, que a percepção de qualidade de vida no trabalho, para os expatriados, está relacionada com uma missão que atenda às expectativas de seu desenvolvimento; permita o cuidado com a família; promova a preparação e o planejamento da expatriação; possibilite o desenvolvimento de novas habilidades profissionais e pessoais; e possibilite aumentar a rede de relacionamentos, o chamado networking.

No entanto, dentre essas expectativas, estão ocorrendo apenas a possibilidade de aumento de networking e o aprendizado informal, não planejado, o que é preocupante, uma vez que esses profissionais estão se desenvolvendo interculturalmente, aprendendo a lidar com pessoas de diferentes culturas e formas de trabalhar, que são características muito procuradas nos profissionais nos dias atuais. Sendo assim, a Ind. M. pode acabar perdendo seu investimento, por não oferecer itens considerados importantes para a qualidade de vida no trabalho.

Atualmente, a Ind. M. busca aumentar a QVT dos expatriados oferecendo-lhes benefícios como a definição de moradia e transporte no país de destino. Porém, conforme a gestora entrevistada, a empresa está consciente de que esses benefícios são insuficientes para conciliar a expectativa do expatriado com a sua missão e sua adaptação à nova cultura.

Além da necessidade de criar políticas mais claras para promoção da QVT, a qualidade de vida no trabalho considerada pelo Departamento de RH de origem deve ser explicada para o RH anfitrião, uma vez que cada país tem a sua percepção sobre o conceito, dependendo da cultura local. Dessa forma, ainda que trabalhe em favor da qualidade de vida dos funcionários locais, o RH pode deixar de suprir as expectativas dos profissionais expatriados. 


\section{Graziele Zwielewski \& Suzana da Rosa Tolfo}

A capacidade de compreender ambas as culturas e considerar os seus elementos parece ser necessária para maior competitividade dos departamentos responsáveis pelas expatriações. Através de iniciativas do RH de origem, com ou sem parceria com o RH anfitrião, as empresas podem antever dificuldades e criar serviços buscando uma maior qualidade de vida no trabalho do expatriado. O RH de origem pode orientar RHs de destino para executarem e controlarem os serviços, ou criar um representante do RH de origem no país de destino, para cuidar dos expatriados, assim como é possível contratar empresa especializada em suprir esses cuidados interculturais.

Entre os países da Europa, as diferenças culturais e de legislações são minimizadas por pactos e acordos comuns, e isso reduz riscos com vistos, adaptação etc. Mas, para brasileiros expatriados para Índia e China, além das dificuldades mencionadas, tem-se a diferença de legislação. Outro aspecto é que, conforme Minayo (2000), a QVT depende da relação social que se estabelecerá e de como os indivíduos do país anfitrião irão enxergar os expatriados. No entanto, como os expatriados conseguirão se relacionar e se sentir inseridos socialmente, se não forem fluentes no idioma local e não compreenderem alguns comportamentos dos locais?

A qualidade de vida no trabalho não depende de iniciativas isoladas, portanto, ações antiestresse, como oferecer comida brasileira no país de destino, apenas amenizam os problemas causados por um ambiente laboral sem qualidade de vida. Sendo assim, é necessário promover um bom processo seletivo, capaz de identificar a maleabilidade adaptativa do candidato; promover bom treinamento intercultural, para desenvolver e fortalecer as competências interculturais do funcionário e de sua família; dar apoio emocional e social no país de destino, além dos cuidados com a carreira do profissional. Para que essas iniciativas aconteçam, é necessário que a ideia de QVT integre as diretrizes administrativas e os objetivos e modelo de gestão da empresa. Caso contrário, as ações se tornam paliativas.

Além desses fatores, percebeu-se forte presença do paroquialismo e preconceito dos brasileiros às diferentes formas de viver, comer, agir e conviver do indiano e do chinês. Como os profissionais iriam reagir, se estivessem em outro país? Seriam também preconceituosos? Ou será que nós, brasileiros, é que seríamos o alvo do preconceito?

Vale lembrar que os profissionais não podem esperar que a empresa cuide completamente da sua qualidade de vida no trabalho e atenda a todas as suas expectativas pessoais e profissionais. Eles também precisam buscar o equilíbrio entre vida pessoal e profissional, buscar um trabalho mais 


\section{QUALIDADE DE VIDA NO TRABALHO DE PROFISSIONAIS EXPATRIADOS PARA ÍNDIA E CHINA}

humanizado, atividades que lhes proporcionem prazer, e cuidar da sua carreira através da autogestão, para não deixar toda responsabilidade pelo seu bem-estar e crescimento nas mãos da organização.

Nesta pesquisa também se percebeu que a expatriação de sucesso e a qualidade de vida no trabalho se vinculam não somente à necessidade logística, técnica e financeira do profissional, mas também às suas questões emocionais, que se relacionam com preparação emocional, desenvolvimento de carreira, reconhecimento profissional, acompanhamento durante a expatriação e cuidados com a família. No entanto, a empresa possui uma equipe de RH muito reduzida, e por isso, registra-se a importância de haver profissionais com formação na área de ciências humanas fazendo parte da equipe do Departamento de Expatriados.

Outra lacuna, percebida entre a literatura e a prática da Ind. M., foi a de serviços destinados à promoção da inserção social do expatriado e de sua família no país de destino. Mas cabe aqui um destaque maior à constatação de que o processo de expatriação ainda é pouco profissionalizado. A Ind. M. oferece algum grau de QVT, mas com muitas limitações, o que causa impactos na qualidade de vida no trabalho. Dessa forma, para avaliação e melhora da QVT, sugere-se que sejam considerados os elementos de Walton adaptados à diferença cultural existente, e sejam considerados o sentido do trabalho e a importância da adaptação cultural do profissional, esta última dependente dos três novos conceitos propostos - a integração social intercultural, os cuidados com a família e a comunicação intercultural, com objetivo de buscar o ajustamento cultural dos profissionais expatriados, que, conforme Ali, Van der Zee e Sanders (2003), é o resultado de todo processo de adaptação.

Para finalizar, este trabalho apresentou algumas limitações importantes a serem consideradas: todos os entrevistados são funcionários de uma mesma organização, e assim, a pesquisa com profissionais de outras organizações pode apresentar diferentes resultados. Outra limitação é o fato de as entrevistas terem sido feitas on-line, sem contato direto com o entrevistado.

Assim, como sugestões para novos estudos e intervenções, apresenta-se as seguintes questões:

a) a relação entre a qualidade de vida no trabalho dos expatriados que passam pela preparação intercultural e a dos que não passam pela preparação;

b) a relação existente entre um determinado perfil profissional e a sua capacidade de se adaptar ao país anfitrião e estar mais propício a vivenciar maior QVT, mesmo em um país diferente. Teriam as novas gerações mais facilidade para adaptar-se? 


\section{Graziele Zwielewski \& Suzana da Rosa Tolfo}

c) o estudo sobre a relação entre a qualidade de vida no trabalho e planos de carreira mais estruturados, para constatar se realmente o planejamento e direcionamento da carreira é um elemento tão fundamental como apontado pelos entrevistados neste trabalho;

d) o desenvolvimento de metodologias para atuação do RH Internacional, voltadas à promoção de QVT dos expatriados (programa de preparação do profissional e da família para missão; cursos para desenvolver a capacidade de lidar com estressores; desenvolvimento de novas habilidades para lidar com a nova rotina e novo contexto cultural; formas de avaliação do desempenho do expatriado; informativos para manter o expatriado atualizado sobre as novas tecnologias usadas na empresa, no seu país de origem; programas de tutores ou mentores para esses profissionais; planejamento de carreira e preparação para repatriação). Atualmente, muitas empresas já atuam como prestadoras de serviços oferecendo soluções interculturais, mas qual seria a melhor forma de oferecer esses serviços? Existe alguma metodologia que ofereça maior retorno e garantia de QVT?

e) nesta pesquisa pôde ser observado que os profissionais se dispõem a participar da missão de expatriação, mas, além da empregabilidade e do aprendizado cultural, não se consegue mensurar o retorno para a carreira desses profissionais; então, qual o motivo de esses profissionais terem aceitado o convite para serem expatriados? Seria pelo seu comprometimento com a organização? A expatriação para a Índia e China são apenas "provações" necessárias para poderem alcançar países melhores, em outra oportunidade de expatriação?

Sendo assim, considera-se que os objetivos deste trabalho foram atingidos, uma vez que a pergunta levantada pelas pesquisadoras foi respondida no corpo do trabalho, e conclui-se que, na avaliação da QVT de um profissional expatriado, além dos indicadores sugeridos por Walton (1979), deveriam ser incluídos, como importantes para a adaptação cultural, o nível de inserção social do profissional e de sua família, a capacidade do profissional e de sua família não apenas em se comunicar, mas também de conseguir expressar seus sentimentos em outro idioma; e o sentido desse trabalho, ou seja, os objetivos pessoais do profissional com a expatriação. 
QUALIDADE DE VIDA NO TRABALHO DE PROFISSIONAIS EXPATRIADOS PARA ÍNDIA E CHINA

\section{REFERÊNCIAS}

ABBOTT, G. N.; STENING, B.W.; ATKINS, P. W. B.; GRANT, A. M. Coaching expatriate managers for success: adding values beyond training and mentoring. Asia Pacific Journal of Human Resources, v. 44, p. 295-317, 2006.

ALBUQUERQUE, F. J. B.; VIEIRA, J. R.; MARTINS, C. R.; NEVES, M. T. de S. A qualidade de vida subjetiva de agricultores. In: KRUTZEN, E. C.; VIEIRA, S. B. (Orgs.). Psicologia social, clínica e saúde mental. João Pessoa: Editora Universitária UFPB, 2007, p.160-179.

ALI, A. J.; VAN DER ZEE, K; SANDERS, G. Determinants of intercultural adjustment among expatriate spouses. International Journal of Intercultural Relations, September, issue 5, v.27, p. 563-580, 2003.

ARAUJO, B. F. V. B. de; BILSKY, W.; MOREIRA, L. M. C. de O. Valores pessoais como antecedentes da adaptação transcultural de expatriados. RAM-Revista de Administração Mackenzie, v. 12(3), p. 69-95, 2012. Disponível em: <www.scielo.br/scielo.php?pid=S1678-

69712012000300005\&script=sci_arttext $>$. Acesso em: 10 set. 2013.

BACKER, J. C.; IVANCEVICH, J. M. The assignment of american executives abroad: systematic, haphazard, or chaotic? California Management Review, vol. 13, n. 3, p. 39-41, 2012.

BENSON, J. Measuring cross-cultural adjustment: The problem of criteria. International Journal of Intercultural Relations, v. 2, p. 21-37, 1978.

BERRY, J. W. Migração, aculturação e adaptação. In: Psicologia, e/imigração e cultura. São Paulo: Casa do Psicólogo, p. 29-45, 2004.

BLACK, S. J. Work role transitions: a study of american expatriate managers in Japan. Journal of International Business Studies, v. 19, p. 277-294, 1988.

BLACK, J.; MENDENHALL, M.; ODDOU, G. Toward a comprehensive model of international adjustment: an integration of multiple theoretical perspective, v. 16(2), p. 291-317, 1991. Retrieved January, 17, 2013, from <https://www.jstor.org/stable/258863?seq=1\#page_scan_tab_contents>.

BRASIL. Ministério do Trabalho e Emprego (2013). Informe MTE Notícias. Brasília (DF). Disponível em: <http://portal.mte.gov.br/portal-mte/> Acesso em: 16 jan. 2013.

BREW, F. P.; TAN, J.; BOOTH, H.; MALIK, IRUM. The effects of cognitive apraisals of communication competence in conflict interaction: a study involving western and chinese cultures. Journal of Cross-Cultural Psychology, v. 42, n.5, p.856-874, 2011.

BUENO, J.; CORSO, J. M. Del. O processo de expatriação como instrumento de integração de culturas: o caso Renault do Brasil. In: XXVIII ENCONTRO NACIONAL DA ASSOCIAÇÃO NACIONAL DE PÓS-GRADUAÇÃO E PESQUISA EM ADMINISTRAÇÃO 2004. Anais... Curitiba, PR, Brasil, 28. Rio de Janeiro, ANPAD 2004, 1CD-ROM. 


\section{Graziele Zwielewski \& Suzana da Rosa Tolfo}

CALIGIURI, P. M. (2000). Selecting expatriates for personality characteristics: a moderating effect of personality on the relationship between host national contact and cross-cultural adjustment.

Management International Review, v. 40, n.1, p. 61-80, 2000.

CARIGNATO, M. D. R.; PACHECO FILHO, R. A. Psicanálise, cultura e migração. São Paulo: YM Editora \& Gráfica, 2002.

CASO DO ZAGUEIRO poderia ser evitado (2011). In: Minuto L. O povo online. Disponível em: $<$ http://esportes.opovo.com.br/app/esportes/minuto/2011/09/29/noticiaminutol,2215355/caso-dozagueiro-breno-poderia-ter-sido-evitado.shtml>. Acesso em: 10 fev. 2012.

CHEN, H.; CHIU Y-H. (2009). The influence of psychological contracts on the adjustment and organisational commitment among expatriates: An empirical study in Taiwan. International Journal of Manpower, v. 30, Iss: 8, p.797-814.

DUTRA, J. S. (2002). Gestão de pessoas: modelo, processos, tendências e perspectivas. São Paulo: Atlas, 2002.

FERNANDES, E. C. Qualidade de vida no trabalho: como medir para melhorar. Salvador: Casa da Qualidade, Editora Ltda., 1996.

FERREIRA, M. C. A ergonomia da atividade se interessa pela qualidade de vida no trabalho? Reflexões empíricas e teóricas. Cadernos de Psicologia Social do Trabalho, v. 11, p. 83-99, 2008.

FORSTER, N. The myth of the international manager. International Journal of Human Resource Management, v. 1, p. 126-142, 2000.

FRANKEN, I.; COUTINHO, M. da P. L.; RAMOS, N. Migração e qualidade de vida: o pensamento social de brasileiros migrantes. In: KRUTZEN, E. C.; VIEIRA, S. B. (Orgs.). Psicologia social, clínica e saúde mental. João Pessoa: Editora Universitária da UFPB, 2007.

FREITAS, M. E. Multiculturalismo e expatriação nas organizações: vida do executivo expatriado, a festa vestida de riso ou de choro. In: DAVEL, E.; VERGARA, S. C. (Orgs.). Gestão com pessoas e subjetividade. São Paulo: Atlas, cap. 11, p. 289-302, 2001.

Expatriação profissional: o desafio interdependente para empresas e indivíduos (2010). GESRevista Gestão e Sociedade CEPEAD/UFMG, vol. 4, n. 9. Belo Horizonte, Setembro/Dezembro 2010. Disponível em: <www.ges.face.ufmg.br〉. Acesso em: 29 nov. 2013.

GALLON, S.; SCHEFFER, A. B. B. O processo de expatriação de executivos: uma análise dos desafios da repatriação a partir de um estudo de caso de uma empresa do sul do Brasil. Disponível em: <www.ifbae.com.br/congresso7/pdf/B141.pdf.> Acesso em: 23 set. 2013.

REAd | Porto Alegre - Edição 84 - N 2 - Maio / Agosto 2016 - p. 510 - 542 


\section{QUALIDADE DE VIDA NO TRABALHO DE PROFISSIONAIS EXPATRIADOS PARA ÍNDIA E CHINA}

GODIM, S. M. G.; FISCHER, T. O discurso, a análise de discurso e a metodologia do discurso do sujeito coletivo na gestão intercultural. Cadernos Gestão Social, Salvador, v. 2, n. 1, p. 09-26, set. dez. 2009. ISSN: 1982-5447.

GONZÁLEZ, J. M. R.; OLIVEIRA, J. A. de. Os efeitos da expatriação sobre a identidade: estudo de caso. Caderno EBAPE.BR, Rio de Janeiro, dez. 2011, v. 9, n. 4, p. 1122-1135. ISSN 1679-3951.

GRANT-VALLONE, E.J.; ENSHER, E.A. An examination of work and personal life conflict, organizational support, and employee health among international expatriates. International Journal of Intercultural Relations, v. 25, n. 3, p. 261-278, 2001.

HOFSTEDE, G. (2001). Culture's consequences: comparing values, behaviors, institutions and organizations across nations. 2nd. ed. Thousand Oaks: Sage Publications. Retrieved January 16, 2013, from <http://books.google.com.br/books?id=w6z18LJ_1VsC\&printsec=frontcover\&hl=ptPT\&source=gbs_ge_summary_r\&cad=0" $\backslash \mathrm{l}$ "v=onepage \&q\&f=false $>$.

HOMEM, I. D. O processo de expatriação em uma multinacional brasileira do Estado de Santa Catarina: um estudo de caso. 2005. 158 f. Dissertação de Mestrado em Administração. Curso de PósGraduação em Administração, Universidade Federal de Santa Catarina, Florianópolis, 2005.

HOMEM, I. D.; DELLAGNELO, E. H. L. Novas formas organizacionais e os desafios para os expatriados. RAE-Revista de Administração de Empresas. São Paulo, jun. 2006, vol. 5, no. 1, p. 0. ISSN 1676-5648. Disponível em: <http://rae.fgv.br/rae-eletronica/vol5-num1-2006/novas-formasorganizacionais-desafios-para-expatriados>. Acesso em: 23 set. 2013.

HOMEM, I. D.; TOLFO, S. da R. Gestão intercultural: perspectivas para o ajustamento de executivos expatriados. In: XXVIII ENCONTRO NACIONAL DA ASSOCIAÇÃO NACIONAL DE PÓSGRADUAÇÃO E PESQUISA EM ADMINISTRAÇÃO 2004. Anais... Curitiba, PR, Brasil, 28. Rio de Janeiro, ANPAD 2004, 1 CD-ROM.

JOLY, A. Alteridade: ser executivo no exterior. In: CHANLAT, J. (Coord.). O indivíduo na organização. São Paulo: Atlas, 1996.

KANAANE, R. Comportamento humano nas organizações: o homem rumo ao século XXI. São Paulo: Atlas, 1999.

KUBO, E. K. de M. Ajustamento intercultural de executivos japoneses expatriados no Brasil. 2011. 197 f. Tese de Doutorado em Administração. Escola de Administração de Empresas de São Paulo (FGV-EAESP), São Paulo, 2011.

LACOMBE, F. J. M. Dicionário de Administração. São Paulo: Saraiva, 2004.

LAVILLE, C. A.; DIONE. J. A construção do saber: manual de metodologia de pesquisa em ciências humanas. Porto Alegre: Editora Artes Médicas Sul Ltda. Belo Horizonte: Editora UFMG, 1999. 


\section{Graziele Zwielewski \& Suzana da Rosa Tolfo}

LEE, L.; VAN VORST, D. The influences of social capital and social support on expatriates' cultural adjustment: an empirical validation in Taiwan. International Journal of Management, v. 27, n. 3, p. 628-649, 2010.

LEITE, J. V.; FERREIRA, M. C.; MENDES, A. M. Mudando a gestão da qualidade de vida no trabalho. Psicologia, organizações e trabalho, Brasília (DF), v. 9, n. 2, p. 109-123, 2009.

LIMA, M. B.; BRAGA, B. M. (2010). Práticas de recursos humanos do processo de repatriação de executivos brasileiros. Revista de Administração Contemporânea, Rio de Janeiro, dez. 2010, v. 14, n. 6, p.1031-1053. ISSN 1415-6555.

LIMONGI-FRANÇA, A. C. Qualidade de vida no trabalho - QVT: conceitos e práticas nas empresas da sociedade pós-industrial. 2. ed. São Paulo: Atlas, 2004.

LIMONGI-FRANÇA, A. C.; ARELLANO, E. B. Qualidade de vida no trabalho. In: FLEURY, M. T. L. (Coord.). As pessoas na organização, p. 295-306. São Paulo: Editora Gente, 2002.

LIMONGI-FRANÇA, A. C.; ANTONIO, F. A.A.; SCHIRMEISTER, R.. Gestão da Qualidade de Vida no Trabalho: fundamentos, identidade e valores. In: CHAMBEL, M. J. Psicologia da Saúde Ocupacional. Pactor: Lisboa, 2016

LUNA, S. V. de. Planejamento de pesquisa: uma introdução. 7. ed. São Paulo: Educ, 2002.

MACHADO, H. V.; HERNANDES, C. A. Alteridade, expatriação e trabalho: implicações para a gestão organizacional. In: XXVII ENCONTRO NACIONAL DA ASSOCIAÇÃO NACIONAL DE PÓS-GRADUAÇÃO E PESQUISA EM ADMINISTRAÇÃO 2003. Anais... Atibaia, SP, Brasil, 27. Rio de Janeiro, ANPAD, 2004, 1 CD-ROM.

MINAYO, M. Qualidade de vida e saúde: um debate necessário. Revista Ciência e Saúde Coletiva, Rio de Janeiro, 5 (1): 7-18, 2000.

MINAYO, M. C. S.; SANCHES, O. Quantitativo-qualitativo: oposição ou complementaridade? Cadernos de Saúde Pública, Rio de Janeiro, v. 9, n. 3, p. 239-262, jul./set. 1993.

MITREV, S.; CULPEPPER, R. Expatriation in Europe: factors and insigths. The Journal of International Management Studies, v. 7, n. 1, April 2012.

MOL, S.T.; BORN, M.P.; WILLEMSEN, M.E.; VAN DER MOLEN, H.T. Predicting expatriate job performance for selection purposes: a quantitative review. Journal of Cross-Cultural Psychology, v. 36, n.5, p.590-620, 2005.

MORIN, E. (2001). Os sentidos do trabalho. RAE - Revista de Administração de Empresas. São Paulo - jul.-set., v. 41, n. 3, pp. 8-19. Disponível em:

$<$ www.google.com/url?sa=t\&rct=j\&q=\&esrc=s\&source=web\&cd=2\&cad=rja\&ved=0CDgQFjAB\&url =http://www.scielo.br/pdf/rae/v41n3/v41n3a02.pdf\&ei=bRr4UKa1Go6J0QGhh4HgBg\&usg=AFQjCN Huq3Ws9ZHzdgaZUyF_P2n-nD-xZQ\&bvm=bv.41018144,d.eWU>. Acesso em: 17 jan. 2013.

REAd | Porto Alegre - Edição 84 - N 2 - Maio / Agosto 2016 - p. 510 - 542 


\section{QUALIDADE DE VIDA NO TRABALHO DE PROFISSIONAIS EXPATRIADOS PARA ÍNDIA E CHINA}

PELTOKORPI, V.; FROESE, F. Organizational expatriates and self-initiated expatriates: who adjusts better to work and life in Japan? The International Journal of Human Resource Management, v. 20, n. 5, p. 1096-1112, 2009.

PEREIRA, N. A. F.; PIMENTEL, R.; KATO, H. T. Expatriação e estratégia internacional: o papel da família como fator de equilíbrio na adaptação do expatriado. In: ENCONTRO NACIONAL DA ASSOCIAÇÃO NACIONAL DE PÓS-GRADUAÇÃO E PESQUISA EM ADMINISTRAÇÃO 2004, Curitiba, PR, Brasil, 28. Anais... Rio de Janeiros: ANPAD, 1CD-ROM 2004.

RAMALU, S. S. et al. Personality and expatriate performance: the mediating role of expatriate adjustment. The Journal of Applied Business Research, v. 26, n. 6, p. 113-122, 2010.

RAMOS, N. Adaptação, saúde e doença em contexto migratório e intercultural. In: RAMOS, N. Psicologia clínica e da saúde, p. 239-299. Lisboa: Universidade Aberta, 2004.

SAMPAIO, J. dos R. QVT: perspectivas e desafios atuais. Revista Psicologia Organizacional e do Trabalho, Florianópolis, jan.-abr., v. 12(1), 2012.

SANT'ANNA, A. S.; KILIMNIK, Z. M. Qualidade de vida no trabalho: abordagens e fundamentos. Rio de Janeiro: Elsevier; Belo Horizonte, MG: Fundação Dom Cabral, 2011.

SANTOS, C. M. B. de N. (2003). Expatriadas brasileiras nos Estados Unidos: desafios e conquistas. In: XXVII ENCONTRO NACIONAL DA ASSOCIAÇÃO NACIONAL DE PÓS-GRADUAÇÃO E PESQUISA EM ADMINISTRAÇÃO 2003. Anais... Atibaia, SP, Brasil, 27. Rio de Janeiro, ANPAD, 2003, 1 CD-ROM.

SHAY, S.; BAACK, S. An empirical investigation of the relationships between modes and degreeof expatriate adjustment and multiple measures of performance. International Journal of Cross Cultural Management, v. 6, n. 3, p. 275-294, 2006.

SHIH, H.; CHIANG, Y.; HSU, C. High involvement work system, work-family conflict, and expatriate performance - examining Taiwanese expatriates in China. The International Journal of Human Resource Management, v. 21, n. 11, p. 2013-2030, 2010.

TISSOT, P.B.; VIEIRA, G.B.B.; LAZZARI, F.; CAMARGO, M.E. Motivadores e dificuldades do processo de expatriação de executivos brasileiros para Índia. Revista Espacios, v. 35, n.6, p.23, 2014.

TOLFO, S. da R.; SILVA, N.; LUNA, I. N. Cultura organizacional, identidade e qualidade de vida no trabalho: articulações e sugestões de pesquisas em organizações. Pesquisas e Práticas Psicossociais, v. 4, n.1, São Joao Del Rei: Editora, dez. 2009.

TUNG, R. Career issues in international assignments. The Academy of Management Executive, vol. 2, n. 3, p. 241-244, 1998.

REAd | Porto Alegre - Edição 84 - N² 2 - Maio / Agosto 2016 - p. 510 - 542 


\section{Graziele Zwielewski \& Suzana da Rosa Tolfo}

VAN DER ZEE, K.; VAN OUDENHOVEN, J.P. Culture shock or challenge? The role of personality as a determinant of intercultural competence. Journal of Cross-Cultural Psychology, v. 44, n.6, p. 928-940, 2013.

VAN ERP, K., J. P. M; GIEBELS, E.; VAN DER ZEE, K.I.; VAN DUIJIN, M.A.J. Expatriate couples' adjustment: the pros and cons of avoiding interpersonal conflict. In: $22^{\mathrm{ND}}$ ANNUAL INTERNATIONAL ASSOCIATION OF CONFLICT MANAGEMENT CONFERENCE.

Proceedings... Japan, 2009. Retrieved April, 20, 2016 from:

<http://papers.ssrn.com/sol3/papers.cfm?abstract_id=1493513>.

WALTON, R. E. Quality of working life: what is it? Sloan Management Review (pré-1986). 1979.

WANG, X. Expatriate adjustment from a social network perspective: theorical examinations and a conceptual mode. International Journal of Cross Cultural Management. London: Sage

Publications, v. 2, n. 3, p. 321-337, 2002. 